P-ISSN: 2615-1723

E-ISSN: 2615-1766

April 2019
Jurnal Riset Pendidikan Dasar

02 (1), (2019) 48-53

Submitted: Februari, Accepted Maret, Published: April

\title{
PENGARUH MODEL PEMBELAJARAN BERBASIS BUDAYA TUDANG SIPULUNG TERHADAP PENGUASAAN KONSEP IPA KELAS IV SD INPRES BONTOMANAI MAKASSAR
}

\author{
Evi Ristiana ${ }^{1}$, Herminar $^{2}$, Muhammad Nasrul $^{3}$ \\ Program Studi Pendidikan Dasar, Pascasarjana Universitas Muhammadiyah Makassar \\ E-mail: eviristianaunismuh9@gmail.com
}

\begin{abstract}
Abstrak
Penelitian ini bertujuan untuk mengetahui pengaruh dari pelaksanaan model pembelajaran berbasis budaya tudang sipulung terhadap penguasaan konsep IPA pada materi struktur dan fungsi bagian tumbuhan siswa kelas IV SD Inpres Bontomanai Makassar. Jenis penelitian ini adalah jenis penelitian eksperimen menggunakan desain penelitian Pretest-Posttest Control Group Design. Prosedur penelitian tahap persiapan, tahap pelaksanaan, dan menganalisis data penguasaan konsep. Subjek dalam penelitian ini adalah murid kelas IV SD Inpres Bontomanai Makassar. Hasil penelitian menunjukkan bahwa pada penguasaan konsep Pretest terdiri dari 33,33\% yang memenuhi kriteria ketuntasan minimal (KKM) atau berada kategori sangat rendah. Secara klasikal belum terpenuhi karena nilai rata-rata diperoleh sebesar 65,41 . Sedangkan pada hasil Posttest terdiri dari $83,33 \%$ telah memenuhi KKM dan secara klasikal telah terpenuhi yaitu dengan nilai rata-rata 77,08 pada kategori tinggi. Berdasarkan hasil penelitian tersebut, dapat disimpulkan hasil belajar murid kelas IV SD Inpres Bontomanai Makassar melalui penggunaan model pembelajaran berbasis budaya tudang sipulung mengalami peningkatan.
\end{abstract}

Kata kunci : Model Pembelajaran Berbasis Budaya Tudang Sipulung, Penguasaan Konsep

\section{THE EFFECT OF TUDANG SIPULUNG CULTURAL LEARNING MODEL ON THE POWER OF CLASS IV SCIENCE CONCEPT SD INPRES BONTOMANAI MAKASSAR}

\footnotetext{
Abstract

This study aims to determine the effect of the implementation of the culture-based learning model of scavengers on mastery of the science concept in the material structure and function of plant parts of fourth grade students of SD Inpres Bontomanai Makassar. This type of research is a type of experimental research using the research design PretestPosttest Control Group Design. Procedure for research preparation phase, implementation phase, and analyzing data mastery concept. The subjects in this study were fourth graders of SD Inpres Bontomanai Makassar. The results showed that the mastery of the Pretest concept consisted of 33.33\% who met the minimum completeness criteria (KKM) or were in a very low category. Classically it has not been fulfilled because the average value obtained is 65.41. While the results of the Posttest consisted of $83.33 \%$ had met the KKM and classically had been fulfilled with an average value of 77.08 in the high category. Based on the results of these studies, it can be concluded that the learning outcomes of fourth grade students of SD Inpres Bontomanai Makassar through the use of the scavenging culture-based learning model have increased.
}

Key Word: Tudang Sipulung Culture Based Learning Model, Mastery of Concepts 


\section{PENDAHULUAN}

Pendidikan menjadi salah satu modal penting untuk memajukan sebuah bangsa karena kesejahteraan dan kemajuan sebuah bangsa dapat dilihat dari tingkat pendidikannya. Pendidikan memegang peranan penting dalam menciptakan individu berkualitas. Pendidikan memerlukan inovasiinovasi yang sesuai dengan kemajuan ilmu pengetahuan dan teknologi. Dasar perkembangan ilmu pengetahuan dan teknologi, ilmu pengetahuan dan teknologi berkembang karena dalam pendidikan formal memberi kesempatan kepada setiap peserta didik dalam mencari dan mendorong untuk setiap kegiatan penambahan wawasan secara mandiri. Pendidikan formal memiliki beragam pengetahuan dan penerapannya di dalam hidup atau kehidupan karena dalam pendidikan formal seharusnya seluruh bentuk pembelajaran mampu diarahkan penerapannya dalam kehidupan .

Pembelajaran IPA dapat lebih mudah dipahami oleh siswa dengan penggunaan model pembelajaran berbasis BTS (budaya tudang sipulung). Penggunaan model pembelajaran yang bervariasi akan antusias siswa dalam mengikuti proses pembelajaran.

Penelitian yang ditulis oleh Ristiana pada tahun 2017 penggunaan model pembelajaran berbasis budaya tudang sipulung a memiliki dampak atau pengaruh yang signifikan dalam meningkatkan kemampuan kognitif mahasiswa PGSD Universitas Muhammadiyah Makassar. Hasil penelitian tersebut menunjukkan bahwa berdasarkan nilai-nilai rata-rata kemampuan kognitif mahasiswa setelah menggunakan model BTS adalah 84,4 dengan kualitas sangat baik. Berdasarkan data tersebut menunjukkan penggunaan model pembelajaran berbasis budaya tudang sipulung meningkatkatkan kemampuan kognitif.

Model pembelajaran berbasis budaya tudang sipulung (BTS) meningkatkan kemampuan pemahaman siswa karena pada sintaks model pembelajaran BTS ada kegiatan kelompok untuk melakukan kerja sama untuk mencari penyelesaian masalah.Kemudian di lanjutkan dengan berbagai informasi dengan tutor sebaya kepada sesama anggota kelompok. Aktifitas siswa pada sintaks ketika menuju adanya learning by doing dan learning together. Dengan demikian informasi yang di terima siswa bukan hanya penyampaian dari guru, tetapi berasal dari kegiatan belajar sendiri dan diskusi dengan teman kelompok (Ristiana, 2017). Hal ini sejalan dengan (Arends,2008) bahwa kerja kooperatif yang terjadi dalam kelompok mendorong mahasiswa untuk mengembangkan keterampilan berpikir dan keterampilan sosial

\section{METODE PENELITIAN}

Jenis penelitian ini adalah jenis penelitian True Eksperimental Design menggunakan desain penelitian preeksperimen Pretest-Posttest Control Group Design. Prosedur penelitian tahap persiapan, tahap pelaksanaan, dan tahap analisis. Subjek dalam penelitian ini adalah murid kelas IV SD Inpres Bontomanai Makassar sebanyak 12 orang, setelah data dari seluruh responden atau sumber data lain terkumpul maka dilakukan analisis data deskriptif dan analisis tes penguasaan konsep, uji-t.

\section{HASIL DAN PEMBAHASAN}

\section{Hasil}

\section{Deskripsi Keterlaksanaan Perangkat \\ Pembelajaran}

Hasil penelitian ini diperoleh penerapan perangkat pembelajaran menggunakan model pembelajaran berbasis budaya tudang sipulung untuk mengetahui pengaruhnya terhadap penguasaan konsep IPA siswa kelas IV SD Inpres Bontomanai Makassar. Perangkat pembelajaran yang digunakan pada penelitian ini adalah RPP (Rencana Pelaksanaan Pembelajaran) disertakan dengan LKPD (Lembar Kerja Peserta Didik). Hasil dan analisis data penelitian dibuat berdasarkan data yang diperoleh dari kegiatan penelitian tentang pengaruh model pembelajaran berbasis 
Jurnal Riset Pendidikan Dasar, 02 (1), April 2019 (48-53)

Evi Ristiana, Herminar, Muhammad Nasrul

budaya tudang sipulung terhadap penguasaan

Bontomanai Makassar. Penelitian ini konsep IPA siswa pada materi struktur dan dilaksanakan selama sepuluh kali pertemuan. fungsi bagian tumbuhan kelas IV SD Inpres

Deskripsi Aktivitas belajar hasil observasi

Tabel 1. Distribusi frekuensi dan persentase aktivitas belajar selama penelitian berlangsung

\begin{tabular}{|c|c|c|c|c|c|c|c|}
\hline \multirow{2}{*}{ No } & \multirow{2}{*}{ Aktivitas } & \multicolumn{4}{|c|}{ Pertemuan/Frekuensi } & \multirow{2}{*}{ Rata-Rata } & \multirow{2}{*}{ Persen (\%) } \\
\hline & & I & II & III & IV & & \\
\hline 1 & Menanggapi apersepsi dari guru & 8 & 11 & 10 & 12 & 10.25 & $85.41 \%$ \\
\hline 2 & $\begin{array}{l}\text { Memperhatikan materi yang dijelaskan } \\
\text { Aktif mengerjakan soal latihan yang }\end{array}$ & 10 & 12 & 11 & 12 & 11.25 & $93.75 \%$ \\
\hline 3 & $\begin{array}{l}\text { diberikan } \\
\text { Masih membutuhkan bimbingan }\end{array}$ & 10 & 10 & 12 & 12 & 11 & $91.67 \%$ \\
\hline 4 & dalam mengerjakan soal & 10 & 9 & 7 & 4 & 7.5 & $62.50 \%$ \\
\hline 5 & $\begin{array}{l}\text { Aktif dalam kegiatan diskusi } \\
\text { Mengerjakan aktivitas lainyang tidak } \\
\text { berhubungan dengan proses }\end{array}$ & 9 & 9 & 11 & 12 & 10.25 & $85.41 \%$ \\
\hline 6 & pembelajaran & 3 & 2 & 0 & 0 & 1.25 & $10.41 \%$ \\
\hline 7 & keluar masuk kelas & 2 & 0 & 1 & 0 & 0.75 & $6.25 \%$ \\
\hline
\end{tabular}

Deskripsi Hasil Keterlaksanaan Proses Pembelajaran dengan Model Pembelajaran Berbasis Budaya Tudang Sipulung

Tabel 2. Frekuensi dan Persentase Keterlaksanaan Model Pembelajaran

\begin{tabular}{llllllll}
\cline { 3 - 6 } NO & \multirow{2}{*}{ Pengamatan } & \multicolumn{9}{c}{ Pertemuan/Frekuensi } & \multirow{2}{*}{ Rata-Rata } & \multirow{2}{*}{ Persen (\%) } \\
\cline { 3 - 6 } & & I & II & III & IV & & \\
\hline 1 & Kegiatan awal & 17 & 18 & 19 & 20 & 18,5 & $92,50 \%$ \\
2 & Kegiatan Inti & 14 & 14 & 14 & 16 & 14,5 & $90,62 \%$ \\
3 & Kegiatan penutup & 6 & 7 & 8 & 6 & 6,75 & $84,37 \%$ \\
\hline
\end{tabular}

\section{NILAI STATISTIK PENGUASAAN KONSEP (PRETEST)}

Tabel 3. Distribusi Nilai statistik penguasaan konsep kelompok control

\begin{tabular}{lll}
\hline No. & Kategori nilai statistik & Nilai \\
\hline 1. & Nilai tertinggi & 85 \\
2. & Nilai terendah & 50 \\
3. & Nilai rata-rata & 72 \\
4 & Standar deviasi & 75 \\
\hline
\end{tabular}

Berdasarkan tabel di atas bahwa nilai ratarata penguasaan konsep padakelompok control adalah 72 . Kemudian skor tertinggi dicapai siswa adalah 85 dan skor terendah 50 .

Berdasarkan tabel di atas bahwa nilai ratarata penguasaan konsep padakelompok eksperimen adalah 65 . Kemudian skor tertinggi dicapai siswa adalah 85 dan skor terendah 50 .
Tabel 4. Distribusi Nilai statistik penguasaan konsep kelompok Eksperimen

\begin{tabular}{lll}
\hline No. & Kategori Nilai Statistik & Nilai \\
\hline 1. & Nilai tertinggi & 85 \\
2. & Nilai terendah & 50 \\
3. & Nilai rata-rata & 65 \\
4 & Standar deviasi & 75 \\
\hline
\end{tabular}

\section{NILAI STATISTIK PENGUASAAN KONSEP (POSTTEST)}

Berdasarkan tabel di atas bahwa nilai ratarata penguasaan konsep pada kelompok kontrol adalah 77 . Kemudian skor tertinggi dicapai siswa adalah 95 dan skor terendah 60 . 
Jurnal Riset Pendidikan Dasar, 02 (1), April 2019 (48-53)

Evi Ristiana, Herminar, Muhammad Nasrul

Tabel 5. Distribusi Nilai statistik penguasaan konsep kelompok kontrol

\begin{tabular}{lll}
\hline No. & Kategori nilai statistic & Nilai \\
\hline 1. & Nilai tertinggi & 95 \\
2. & Nilai terendah & 60 \\
3. & Nilai rata-rata & 77 \\
4 & Standar deviasi & 75 \\
\hline
\end{tabular}

Tabel 6. Distribusi Nilai statistik penguasaan konsep kelompok eksperimen

\begin{tabular}{|l|l|l|}
\hline No. & Kategori nilai statistic & Nilai \\
\hline 1. & Nilai tertinggi & 95 \\
\hline 2. & Nilai terendah & 62 \\
\hline 3. & Nilai rata-rata & 82 \\
\hline 4 & Standar deviasi & 75 \\
\hline \multicolumn{2}{|c|}{ Berdasarkan tabel di atas bahwa nilai rata- }
\end{tabular}

rata penguasaan konsep pada kelompok eksperimen adalah 82. Kemudian skor tertinggi dicapai siswa adalah 95 dan skor terendah 62

\section{KATEGORI PENGUASAAN KONSEP (PRETEST)}

Tabel 7. Distribusi dan frekuensi kategori penguasaan konsep kelompok kontrol

\begin{tabular}{lllll}
\hline No & Interval Nilai & Kategori & Frekuensi & Persentase(\%) \\
\hline 1. & $50-57$ & Sangat rendah & 1 & $8.33 \%$ \\
2. & $58-64$ & Rendah & 1 & $8.33 \%$ \\
3. & $65-71$ & Sedang & 3 & $25.00 \%$ \\
4. & $72-78$ & Tinggi & 3 & $25.00 \%$ \\
5. & $79-86$ & Sangat Tinggi & 4 & $33.33 \%$ \\
\hline Jumlah & & 12 & $100 \%$
\end{tabular}

Berdasarkan tabel di atas dapat digambarkan bahwa dari 12 siswa kelas IV pada kelompok kontrol terdapat terdapat 1 siswa mendapatkan nilai sangat rendah atau $8.33 \%$, kemudian 1 siswa mendapat nilai rendah atau $8.33 \%$, dan terdapat 3 siswa yang mendapat nilai sedang atau $25.00 \%$, sedangkan 3 siswa yang

mendapat nilai tinggi atau $25.00 \%$. Selanjutnya, terdapat 4 siswa yang mendapat nilai sangat tinggi atau $33.33 \%$. hal ini menunjukkan bahwa, hasil penguasaan konsep IPA pada siswa kelas IV termasuk kategori sangat tinggi yaitu $33.33 \%$ atau 4 siswa dari 12 siswa dengan skor rata-rata 72 .

Tabel 8. Distribusi dan frekuensi kategori penguasaan konsep kelompok eksperimen

\begin{tabular}{lllll}
\hline No & Interval Nilai & Kategori & Frekuensi & Persentase \\
\hline 1. & $50-57$ & Sangat rendah & 4 & $33.33 \%$ \\
2. & $58-64$ & Rendah & 1 & $8.33 \%$ \\
3. & $65-71$ & Sedang & 3 & $25.00 \%$ \\
4. & $72-78$ & Tinggi & 1 & 8.33 \\
5. & $79-86$ & Sangat Tinggi & 3 & $25.00 \%$ \\
\hline Jumlah & & 12 & $100 \%$
\end{tabular}

Berdasarkan tabel di atas dapat digambarkan bahwa dari 12 siswa kelas IV pada kelompok eksperimen terdapat terdapat 4 siswa mendapatkan nilai sangat rendah atau $33.33 \%$, kemudian 1 siswa mendapat nilai rendah atau $8.33 \%$, dan terdapat 3 siswa yang mendapat nilai sedang atau $25.00 \%$, sedangkan 1 siswa yang mendapat nilai tinggi atau $8.33 \%$. Selanjutnya, terdapat 3 siswa yang mendapat nilai sangat tinggi atau $25.00 \%$. Hal ini menunjukkan bahwa, hasil penguasaan konsep IPA pada siswa kelas IV termasuk kategori sangat rendah yaitu $33.33 \%$ atau 4 siswa dari 12 siswa dengan skor rata-rata 65 .

\section{Kategori Penguasaan Konsep (Posttest)}

Copyright $@ 2019$, JRPD, ISSN 2615 - 1723 (Print), ISSN 2615 - 1766 (Online) 
Jurnal Riset Pendidikan Dasar, 02 (1), April 2019 (48-53)

Evi Ristiana, Herminar, Muhammad Nasrul

Tabel 9. Distribusi dan Frekuensi Kategori Penguasaan Konsep Kelompok Kontrol

\begin{tabular}{lllll}
\hline No & Interval Nilai & Kategori & Frekuensi & Persentase \\
\hline 1. & $60-67$ & Sangat rendah & 3 & $25.00 \%$ \\
2. & $68-75$ & Rendah & 4 & $33.33 \%$ \\
3. & $76-83$ & Sedang & 1 & $8.33 \%$ \\
4. & $84-91$ & Tinggi & 3 & $25.00 \%$ \\
5. & $92-99$ & Sangat Tinggi & 1 & $8.33 \%$ \\
\hline Jumlah & & $\mathbf{1 2}$ & $\mathbf{1 0 0 \%}$ \\
\hline
\end{tabular}

Berdasarkan tabel di atas . dapat mendapat nilai tinggi atau $25.00 \%$. Selanjutnya, digambarkan bahwa dari 12 siswa kelas IV pada terdapat 1 siswa yang mendapat nilai sangat tinggi kelompok kontrol terdapat terdapat 3 siswa atau 8.33\%. Hal ini menunjukkan bahwa, hasil mendapatkan nilai sangat rendah atau 25.00\%, penguasaan konsep IPA pada siswa kelas IV kemudian 4 siswa mendapat nilai rendah atau termasuk kategori rendah yaitu $33.33 \%$ atau 4 $33.33 \%$, dan terdapat 1 siswa yang mendapat nilai siswa dari 12 siswa dengan skor rata-rata 77 .

sedang atau $8.33 \%$, sedangkan 3 siswa yang

Tabel 10. Distribusi dan Frekuensi Kategori Penguasaan Konsep Kelompok Eksperimen

\begin{tabular}{lllll}
\hline No & Interval Nilai & Kategori & Frekuensi & Persentase \\
\hline 1. & $65-71$ & Sangat rendah & 2 & $16.67 \%$ \\
2. & $72-79$ & Rendah & 3 & $25.00 \%$ \\
3. & $80-87$ & Sedang & 1 & $8.33 \%$ \\
4. & $88-95$ & Tinggi & 5 & $41,67 \%$ \\
5. & $96-102$ & Sangat Tinggi & 1 & $8.33 \%$ \\
\hline Jumlah & & $\mathbf{1 2}$ & $\mathbf{1 0 0} \%$
\end{tabular}

Berdasarkan tabel di atas dapat digambarkan bahwa dari 12 siswa kelas IV pada kelompok eksperimen terdapat terdapat 2 siswa mendapatkan nilai sangat rendah atau $16.67 \%$, kemudian 3 siswa mendapat nilai rendah atau $25.00 \%$, dan terdapat 1 siswa yang mendapat nilai sedang atau $8.33 \%$, sedangkan
5 siswa yang mendapat nilai tinggi atau $41.67 \%$. Selanjutnya, terdapat 1 siswa yang mendapat nilai sangat tinggi atau $8.33 \%$. Hal ini menunjukkan bahwa, hasil penguasaan konsep IPA pada siswa kelas IV termasuk kategori tinggi yaitu $41.67 \%$ atau 5 siswa dari 12 siswa dengan skor rata-rata 82 .

\section{Ketuntasan Penguasaan Konsep}

Tabel 11 keuntasan penguasaan konsep (pretest)

\begin{tabular}{|c|c|c|c|c|c|}
\hline \multirow[t]{2}{*}{ No } & \multirow[t]{2}{*}{ Kategori Ketuntasan } & \multicolumn{2}{|c|}{ Kelompok Kontrol } & \multicolumn{2}{|c|}{ Kelompok Eksperimen } \\
\hline & & $\mathbf{F}$ & $\%$ & $\mathbf{F}$ & $\%$ \\
\hline 1. & Tidak tuntas & 6 & $50.00 \%$ & 8 & $66.67 \%$ \\
\hline 2. & Tuntas & 6 & $50.00 \%$ & 4 & $33.33 \%$ \\
\hline Juı & & 12 & $100 \%$ & 12 & $100 \%$ \\
\hline
\end{tabular}

Berdasarkan tabel di atas digambarkan siswa. Sedangkan persentase ketuntasan bahwa pada kelompok kontrol hasil pretest penguasaan konsep kelompok eksperimen menunjukkan siswa dalam kategori tuntas menunjukkan bahwa, siswa yang termasuk berjumlah 6 siswa dengan persentase kategori tuntas berjumlah 4 siswa atau ketuntasan mencapai $50.00 \%$. Sedangkan $33.33 \%$. Kategori siswa yang tidak tuntas siswa yang termasuk kategori tidak tuntas berjumlah 8 siswa atau $666.7 \%$ dari jumlah sebesar $50.00 \%$ atau 6 siswa dari jumlah 12 siswa 12 siswa. 
Jurnal Riset Pendidikan Dasar, 02 (1), April 2019 (48-53)

Evi Ristiana, Herminar, Muhammad Nasrul

Tabel 11 Ketuntasan Penguasaan Konsep (Posttest)

\begin{tabular}{|c|c|c|c|c|c|}
\hline \multirow[t]{2}{*}{ No } & \multirow[t]{2}{*}{ Kategori Ketuntasan } & \multicolumn{2}{|c|}{ Kelompok Kontrol } & \multicolumn{2}{|c|}{ Kelompok Eksperimen } \\
\hline & & $\mathbf{F}$ & $\%$ & $\mathbf{F}$ & $\%$ \\
\hline 1. & Tidak tuntas & 3 & $25.00 \%$ & 2 & $16.67 \%$ \\
\hline 2. & Tuntas & 9 & $75.00 \%$ & 10 & $83.33 \%$ \\
\hline \multicolumn{2}{|c|}{ Jumlah } & 12 & $100 \%$ & 12 & $100 \%$ \\
\hline
\end{tabular}

Berdsarkan tabel di atas digambarkan bahwa pada kelompok kontrol hasil posttest menunjukkan siswa dalam kategori tuntas berjumlah 9 siswa dengan persentase ketuntasan mencapai $75.00 \%$. Sedangkan siswa yang termasuk kategori tidak tuntas sebesar $25.00 \%$ atau 3 siswa dari jumlah siswa 12 siswa. Sedangkan persentase ketuntasan penguasaan konsep kelompok eksperimen menunjukkan bahwa, siswa yang termasuk kategori tuntas berjumlah 10 siswa atau $83.33 \%$. Kategori siswa yang tidak tuntas berjumlah 2 siswa atau $16.67 \%$ dari jumlah siswa 12 siswa. Apabila tabel 4.6. dikaitkan dengan indikator ketuntasan penguasaan konsep IPA pada materi struktur dan fungsi bagian tumbuhan pada kelas IV setelah dilakukan model pembelajaran berbasis budaya tudang sipulung pada kelompok eksperimen telah memenuhi indikator secara klasikal.

\section{Uji Hipotesis "Uji-t"}

Pengujian normalitas dari hipotesis dengan memperhitungksn df atau db-nya yaitu bertaraf signifikansi 5\% dengan df sebesar 11 diperoleh harga kritik $\mathrm{t}$ atau tabel pada $\mathrm{t}_{\text {tabel }}$ signifikansi $5 \%$ sebesar $19,67 \%$ pada tabel chi-kuadrat. Nilai $\mathrm{t}\left(\mathrm{t}_{\mathrm{t} \text {.ts }} 5 \%=19,67\right)$ maka dapat diketahui bahwa $t_{0}$ lebih besar lebih besar daripada $t_{\text {tabel }}$ yaitu, $\mathbf{9 4 , 7 5}>19, \mathbf{6 7}$. oleh karena itu, t0 lebih besar daripada ttabel maka hipotesis nihil atau $\mathrm{H}_{0}$ yang diajukan ditolak karena $t_{\text {hitung }}>t_{\text {tabel }}$ dan $\mathrm{H}_{1}$ diterima. Sehingga terdapat perbedaan yang signifikan antara penguasaan konsep sebelum dan setelah penggunaan model pembelajaran berbasis budaya tudang sipulung pada materi struktur dan fungsi bagian tumbuhan kelas IV menunjukkan pengaruhnya secara nyata.

\section{Pembahasan}

Penguasaan konsep sebelum pelaksanaan pembelajaran dengan menerapkan model pembelajaran berbasis budaya tudang sipulung dari 12 siswa sebagai sampel diperoleh 3 siswa yang barada pada kategori penguasaan konsep sangat tinggi, 1 siswa pada kategori tinggi, 3 siswa pada kategori sedang, 1 siswa pada kategori rendah dan 4 siswa pada kategori sangat rendah. Sedangkan penguasaan konsep setelah penerapan model pembelajaran berbasis budaya tudang sipulung diperoleh 1 siswa yang berada pada kategori sangat tinggi, 5 siswa pada kategori tinggi, 1 siswa pada kategori sedang, 3 siswa pada kategori rendah dan 2 siswa pada kategorisangat rendah.

\section{KESIMPULAN}

Berdasarkan hasil penelitian yang dilaksanakan di SD Inpres Bontomanai Makassar kelas IV pada mata pelajaran IPA materi struktur dan fungsi bagian tumbuhan tentang pengaruh model pembelajaran berbasis budaya tudang sipulung, dapat disimpulkan bahwa model pembelajaran berbasis budaya tudang sipulung memiliki pengaruh yang signifikan terhadap hasil belajar siswa kelas IV pada mata pelajaran IPA. Hal ini berdasar pada data-data yang diperoleh setelah diadakan penelitian. Hasil analisis data menunjukkan bahwa hasil pretest, diperoleh nilai rata-rata hasil belajar siswa yaitu 65,41 yang tergolong dalam kategori sangat rendah. Sedangkan nilai rata-rata hasil posttest adalah 82,5 dalam kategori tinggi hal ini menandakan 
Jurnal Riset Pendidikan Dasar, 02 (1), April 2019 (48-53)

Evi Ristiana, Herminar, Muhammad Nasrul

bahwa hasil setelah diberi perlakuan meningkat dengan rentang yang begitu besar.

\section{DAFTAR PUSTAKA}

Akib, I. (2008). Model Pembelajaran matematika Berbasis Budaya Bugis- Makassar. Disertasi tidak diterbitkan. Surabaya: PPS Universitas Negeri Surabaya.

Arikunto, Suharsini. (2007). Penilaian Program Pendidikan. Jakarta : Bumi Aksara.

Arrends, R. (2008). Learning To Teach (Belajar untuk Mengajar) Terjemahan Helly Prayitno. dan Sri Mulyantini Soejipto. Edisi Ketujuh, Buku II. Yogyakarta: Pustaka Pelajar.

Bloom, B.S. (1979). Taxonomy of Educational Objectives. Book I Cognitive Domain. London: Longman Group L.td.

Faisal. (2008). Ruang Publik Poenam Sebagai Bagian Budaya Politik Kontemporer Makassar; SuatuPertarungan Ideologis Menuju Hagemoni. Tesis tidak diterbitkan. PPS fakultas Ilmu Pengetahuan Budaya. Depok. Universitas Indonesia.

Indrawati. (1999). Keterampilan Proses Sains: Tinjauan Kritis dari Teori ke Praktis. Bandung : dirjen Pendidikan Dasar dan Menengah.

Margono. 2010. Metodologi Penelitian Pendidikan. Jakarta: Rineka Cipta.

Mattulada. (1998). Latoa; Suatu Lukisan Analitis Terhadap Antropologi Politik Orang Bugis. Makassar: Hasanuddin University Press.
Mattulada, A. (2015). Latoa - Antropologi Politik Orang Bugis. Yogyakarta: Penerbit Ombak.

Ristiana, E. (2017). Pengembangan Model Pembelajaran Biologi Berbasis Budaya Tudang Sipulung dalam Memberdayakan Kemampuan Pemecahan Masalah, Berpikir Kritis dan Kognitif Mahasiswa Jurusan Biologi Universitas Muhammadiyah Makassar. Disertasi tidak diterbitkan. Malang: PPS Universitas Negeri Malang.

Rusman. (2014). Model-Model Pembelajaran. Jakarta: Rajawali Pres.

Sanjaya,W. (2009) .Penelitian Tindakan Kelas. Jakarta: Kencana.

Slavin, R.E. (2010). Cooperative Learning: Teori, Riset dan Praktik. Terjemahan oleh Nuralita Yusron. 2008. Bandung: Nusa Media.

Sundari, K. (2013). Pengaruh Model Pembelajaran Children Learning In Science terhadap Penguasaan Konsep Siswa Pada Mata Pelajaran Ilmu Pengetahuan Alam Kelas III Di Sekolah Dasar Negeri III Bekasi. Bekasi.

Sugiyono. (2007). Statistika untuk Penelitian. Bandung: Alfabeta.

Sugiyono. (2016). Metode Penelitian Pendidikan. Bandung: Alfabeta.

Tursinawati. (2016). Penguasaan Konsep Hakikat Sains dalam Pelaksanaan Percobaan Pada Pembelajaran IPA di SDN Kota Banda Aceh.Pesona Dasar, 2(4): 74 . 